\title{
Perceived irrelevance and achievement goals: Two mindset variables within attitudinal experiences of life science majors in introductory physics
}

\author{
Andrew J. Mason \\ Department of Physics and Astronomy, University of Central Arkansas, \\ 201 S. Donaghey Avenue, Conway, Arkansas 72035, USA
}

(Received 17 December 2020; accepted 22 July 2021; published 29 September 2021)

\begin{abstract}
This paper is a follow-up to a previous study, in which students (predominately life science majors) were found to self-express achievement goals with regard to a prelab problem-solving exercise in an algebrabased introductory physics course. In this paper, the same sampled population was also asked in the same feedback survey to discuss what portion or portions of the course were relevant to their respective choices of major; in responding, students expressed another aspect of mindset, namely, perceived relevance of the course to their majors. We primarily investigate the difference between 50 students who perceived no relevance of introductory physics to their major and 168 students who perceived some form of relevance. The primary finding was that students who perceive relevance will experience more expertlike shifts than students who do not. In particular, the attitudinal survey's item clusters that pertain to personal interest and real-world connections appear to show the strongest effect. Further examination showed that biology majors and health science majors (two distinctive subpopulations of life science majors) show similar prepost trends for relevance vs irrelevance perceptions, whereas students with a performance achievement goal appeared to bifurcate between a novicelike shift for perceived irrelevance and no attitudinal shift from pre to post for perceived relevance.
\end{abstract}

DOI: 10.1103/PhysRevPhysEducRes.17.020124

\section{INTRODUCTION}

The notion of student mindset [1,2], as recently applied to learning physics [3,4], builds upon research upon students' epistemological views of learning [5] particularly with regard to learning physics [6]. In particular, the notion of student mindset has been recognized as a potential factor for the success of physics majors, both throughout the undergraduate physics major curriculum [7] and extending into graduate school and even career paths for physical science majors [8], The general consensus of the literature appears to be that seeing oneself as a physicist does have an influence upon being successful as a physicist.

\section{A. Two mindset variables: Achievement goals and perceived relevance}

The topic of student mindset, primarily with regard to student beliefs about intelligence, has a very strong presence in psychology literature [1,9]. We focus on two aspects of student mindset in this paper. First, in previous literature [10-13], we discussed the effect of achievement

Published by the American Physical Society under the terms of the Creative Commons Attribution 4.0 International license. Further distribution of this work must maintain attribution to the author(s) and the published article's title, journal citation, and DOI. goals, specifically mastering vs performance achievement goals, on an introductory algebra-based physics course. In this paper, we consider achievement goals alongside a second variable, namely, perceived relevance of physics to students' respective majors [14]. Perceived relevance has been duly noted in terms of students' buy-in and selfperception [15] and clearly identified as a potential issue when interpreting students' content gains. While many other factors of mindset are important to consider for introductory physics [4], this paper will focus on the combined effect of mastery or performance achievement goals and perceived relevance of physics to one's life science major.

The above concerns come to the forefront when considering a research-based implementation of curricular change. Hypothetically, students will become more engaged and have better performance results due to the implementation (as compared to a traditional course plan), but if student mindset variables are not optimal, then the course population may not benefit from the research-based implementations. As an example from previous work [10], students in an introductory algebra-based first-semester physics course were presented with a metacognitive coordinated group problem-solving task [16] working on a context-rich problem [17] at the beginning of their laboratory sections, which was followed by a metacognitive "self-diagnosis" exercise for individual students to consider their respective strengths and weaknesses at the problem 
solving exercise $[18,19]$. In a post-test feedback survey, students self-reported how the exercise helped them in the course; most of them expressed learning orientations that were either mastery-based or performance-based achievement goals [9]. A clear difference between these two achievement goals was visible in results on a validated survey regarding attitudes towards physics [20].

While the average course GPA across both learning orientation groups in the Mason and Bertram study was virtually identical, a borderline result showed that students who had either achievement goal performed marginally better in the course than students who did not express an achievement goal. This result appears to reflect earlier, more detailed studies that also show that, within the scope of a single introductory course, it is simply more important to have either achievement goal than to have neither. For example, findings within a larger sample of introductory psychology students showed that students with primarily mastery orientation, students with primarily performance orientation, and students who were highly motivated in both mastery and performance, all had similar outcomes on achievement measurables, while low-motivated students (akin to the "vague" orientation in Ref. [10]) had significantly poorer results on achievement [21].

While seemingly modest, the results in Ref. [10] suggest that students' respective mindsets may either assist or undermine the pedagogical benefit they receive from research-based instruction. In addition, the algebrabased course was designed for non-physical-science STEM majors, predominately biology and health science majors. It was determined that health science majors tended to fare more poorly [e.g., on Force Concept Inventory (FCI) [22] and course performance], as well as have more novicelike attitudes on the Colorado Learning Attitudes about Science Survey (CLASS) (both pretest and post-test) [20], than did biology majors.

Between the variable of type of life science major and the variable of achievement goals, it becomes clear that (a) certain subpopulations of the student sample may not receive the intended benefit of research-based interventions if they are not explicitly considering mastery of the subject as a goal; and (b) students that are more removed from the natural science setting of introductory physics (i.e., the health science majors, whose concentrations ranged from health administration to pre-physical or occupational therapy to nutrition, etc.) will on average have a harder time being prepared for the course from start to finish than will a life science major that is more clearly linked to natural science (i.e., the biology majors, some of whom were premedical and some of whom were not).

For this paper, we revisit the same population described within the Mason and Bertram study in order to examine perceived relevance of physics to students' chosen major within this population. In combination with achievement goals, perceived relevance may also help to predict whether students' perceptions of learning physics will be more novicelike or expertlike by the end of a first-semester introductory course's instruction. It therefore becomes important both to identify perceived relevance within a population of life science majors and to examine the variable within the other variable of self-expressed achievement goal (mastery, performance, or neither).

\section{B. Theoretical framework for implementation}

The implementation of the problem-solving framework within both this study and the Mason and Bertram study rests upon the notion of cognitive apprenticeship [23], specifically the modeling-coaching-fading model for mentoring a student into mastery of the topic. In the case of physics problem solving, the study focused on the coaching aspect of the cognitive apprenticeship framework via a prelab group-based problem-solving exercise.

Scaffolding of some kind is necessary to ease the students' learning progress as well within the cognitive apprenticeship framework, e.g., in terms of balancing innovation with efficiency [24]. In this particular study, to offer scaffolding for coaching purposes within the cognitive apprenticeship framework, a rubric that was designed to metacognitively "self-diagnose" errors on a quiz $[18,19]$ was adapted to allow individual students to identify their own strengths and weaknesses for a given problem attempt. The need to sustain the intervention from week to week, in order to reinforce students' practices, is also apparent, as a one-time intervention may not be enough to reinforce the exercise's metacognitive skills $[18,19]$. Therefore, the metacognitive exercise may have better results if applied on a weekly basis, e.g., in a recitation setting for a weekly problem solution attempt, and adapted accordingly from a "selfdiagnosis" quiz setting to a self-monitoring task in a worked example setting.

In addition, coordinated group problem solving [16] offers scaffolding in the form of groups working together in a proactive setting. Measures must be taken to prevent a typical pitfall of group work, namely, that one student ends up dominating the workload while others do not contribute (and subsequently, do not learn the material as well). The model for this task, in keeping with the "Minnesota model" for problem solving [25], suggests that students be given "roles" to use and develop these roles mutually with their partners. Alternatively, one may also provide incentive for students to work individually while being allowed to consult with their partners as needed.

Before examining these measures for performance, it must also be considered that students' focus on learning may be affected by certain circumstances, e.g., majoring in something other than physical science (see the next section for specific applications of mindset concerns to this study). Aspects of student mindset, such as achievement goals and perceived relevance, become potential factors in students' 
overall performance. Perceived relevance has recently become a focus within PER literature. More recent efforts include a focus on perceived relevance within well-known attitudinal surveys in physics [26] or in terms of preservice physics teachers' issues with their own perceived relevance of physics to their teaching careers [27]. In particular, it is a concern that life science majors, e.g., premedical students, may see a decline in perceived relevance over the course of a semester, as explicitly detailed by individual items on an attitudinal survey for physics $[6,28]$.

A feedback survey that investigates students' perceived relevance directly, as well as students' achievement goals indirectly, was used to collect data for achievement goals in the previous study [10]. We follow up in this paper on the more direct single-question measurement of students' perceived relevance of physics to their respective majors.

\section{Institutional considerations and limitations on student mindset research}

There are several considerations that must be understood for the context of the following paper, particularly with regard to implementation of the theoretical framework previously described-in particular, much of the framework has primarily been developed in the context of student populations at large research universities, whereas this study is in the context of a primarily undergraduate, regional comprehensive state university. Accordingly, some adaptations must be made to address the institutional differences, some of which offer limitations.

First, not all students in introductory physics are physics majors, or for that matter physical science and engineering majors, such that it is not immediately apparent to students outside of these majors why they need to be in an introductory physics course. A strong example of research on this issue exists within the Introductory Physics for Life Science (IPLS) literature in recent years [29-31], e.g., in the concerns for premedical biology majors and prephysical therapy health science majors. There is extensive literature regarding addressing student mindset-e.g., interviews of biology majors to check for perceived relevance of physics to their career paths [32], as well as coordination with biology faculty for input on which physics topics would more ideally assist biology majors at the introductory level [33]. The notion that performance in introductory physics may be influenced by students' attitudes and interest in physics has been well established in recent literature, e.g., in the setting of a private liberal arts college [34,35] where an IPLS transformation has been shown to improve students' attitudes towards physics.

Second, there is more generally an issue within the imbalance of literature on introductory physics courses, as discussed by Kanim and Cid [36]. For example, among the results found in this study were an overemphasis on research for introductory physics courses concentrated within calculus-based physics, with relatively little focus on algebra-based physics (as well as a very small focus on community college and high school sections of physics). However, many introductory physics courses constructed with a primarily life-science major population are constrained to algebra-based physics contexts, whether administratively or by departmental decision. This may require a change in depth of the content knowledge covered in the course, as well as the expectation level of students' preparedness for the course.

Third, the vast majority of published IPLS research comes from researchers at either large or very large research institutions, with the remaining researchers tending to be based within private liberal arts colleges or similar institutions. The above institution types tend to have very high tuition rates, high standards for acceptance, and relatively low acceptance rates. Other institution types, e.g., regional state universities with higher acceptance rates and lower tuition costs, have relatively little literature in the field. A potential pitfall of this situation is that the solutions proposed by the literature for large research universities do not necessarily work for students who attend other institution types, e.g., because the institutional context of the literature does not match the institutional context of other institutions.

The latter two points are of importance due to their influence on the study, namely, that the host institution is a primarily undergraduate state university with regional focus, and the host department of physics and astronomy is undergraduate only. This means that certain factors within much of the literature cannot be directly replicated. One factor is that simply not having a graduate program means that graduate teaching assistants are not available; undergraduate learning systems are primarily only available for tutoring hours. The host department otherwise does not offer recitation sections and must have faculty teach all laboratory sections. On the other hand, this means that individual faculty members can have full control over in-class interventions, albeit within the limitations of traditional lecture-lab instruction models for large introductory courses.

A second factor is that calculus-based introductory physics is restricted to courses taken by physics majors and a few other majors closely associated with physics (e.g., ACS-accredited tracks within the chemistry major). The life science majors must instead take the introductory algebra-based physics course that is reserved for all other STEM majors. Many IPLS studies at large research universities are largely done on calculus-based IPLS courses, but this is often not possible at other institution types.

As a third factor, not all life science majors at the host institution are the same specific major, as is the case in much of the IPLS literature. Life science majors are split between majors within biology tracks and health science majors within a separate college. Biology majors include 
both pre-professional concentrations, e.g., premedical or predental, and regular biology majors without a preprofessional track. Majors within the health science college includes pre-physical therapy and pre-occupational therapy tracks, as well as several different majors outside of these tracks, e.g., nutrition and health administration. Biology majors and health science majors are roughly equal in population size for most given algebra-based introduction sections. The logical solution is to make two separate course sections that cater, respectively, to these two sets of majors; however, before this can occur, student mindset issues must be addressed for each set of majors in order to optimize the experience in both course sections.

\section{CURRENT RESEARCH GOALS}

In this study, which is a follow-up to Mason and Bertram [10], we examine a question given in a post-test feedback survey: "Which sections of the [course] material did you find related well to the coursework in your major?" While students cited many items within the course that they perceived to be relevant to their respective majors, 50 out of 218 total students stated that they saw no relevance whatsoever to their perceived majors. We therefore look at the major variable of "relevance" versus "irrelevance", i.e., students perceiving any kind of relevance at all vs students who perceived no relevance.

In this paper, we will attempt to answer the following research questions. First, we will see if perceived relevance has a quantitative effect on FCI pre-post conceptual understanding. Second, we will determine if perceived relevance has an effect on pre-post attitudinal shifts measured by the CLASS survey, both overall and on seemingly pertinent item clusters (e.g., personal interest and real-world context). Third, we will look within groups for both choice of life science major (either biology or health science) and achievement goal orientation (framework, performance, or vague), to see if any of these subgroups is particularly affected by perceived relevance.

This paper builds upon Ref. [14], adding the following: a more detailed statistical information (namely, standard error values given in most tables), further explanation of the results in Tables IV and V, more detail about the experimental design, and a more detailed discussion of the results. Limitations on the study, which include institutional limitations, are also discussed.

\section{PROCEDURE}

\section{A. Classroom setup and instruments}

From the period of Spring 2014 to Spring 2017, six semester sections from a single instructor's first-semester introductory algebra-based physics course were sampled. The instructor taught within the context of a traditional lecture-lab format with no recitations, directly teaching all laboratory sections (typically two or three sections
You are studying a herd of bighorn sheep in Alberta, and have found two rams butting heads with each other to establish dominance. Your camera is able to get a high-speed recording of the rams as they take a running start toward each other, on level ground and along a straight line path, before they collide head-on. This way you can use video analysis software to determine how fast each ram was going before the collision. The first ram looks to be about average size for an adult, while the second ram looks to be about $1 / 2$ the size of the first ram, so you estimate the mass of the first ram to be about $90 \mathrm{~kg} *$ and the second ram to be about $45 \mathrm{~kg}$. In your analysis, you see that the second ram was running much faster $(2.10 \mathrm{~m} / \mathrm{s})$ than the first ram was $(0.90 \mathrm{~m} / \mathrm{s})$, such that when they butted heads, the smaller ram was brought to a halt. As a result, you find that you can determine the velocity of the larger ram after the collision.

FIG. 1. Sample context-rich problem used for student metacognition during the first portion of weekly laboratory sections. From Ref. [10].

per semester, 24 students each) as well as a single lecture section attached to all laboratory sections (48-72 students total). Instructor bias between sections is therefore not a factor.

Prior to the beginning of the study, the lecture-lab format of the course's laboratory sections was devoted fully to a lab experiment that was designed to take up the bulk of lab section's time ( 2 h $40 \mathrm{~min}$, once a week). Traditional instruction therefore consisted of students working on a lab experiment during their weekly respective lab sections and then attending three 50-min lectures each week. In terms of content related to life science, the course materials (e.g., the textbook and associated lectures and labs) had minimal physics examples within a life science context, following an order of topics that is typical for physical scientists and engineers in a calculus-based introductory course.

To address this latter issue, the instructor regularly emphasized life science applications of each topic covered in the first-semester section (kinematics, linear dynamics, impulse and momentum, work and energy, rotational statics, rotational kinematics and dynamics, limited thermodynamics topics, and static fluids). This life science coverage would consist of a percentage of in-class worked examples and homework problems.

Since there were no recitation sections, the instructor used the first 50-60 min to implement a prelab problem exercise (see Figs. 1 and 2; also see Ref. [10]). The exercise consisted of presenting students with a context-rich problem [17] that was conceptually connected to the lab experiment that would follow, and having them work on the problem for approximately $45 \mathrm{~min}$. The students would 


\begin{tabular}{|c|c|c|}
\hline $\begin{array}{l}\text { Circle how } \\
\text { much you think } \\
\text { you understood } \\
\text { on: }\end{array}$ & $\begin{array}{l}\text { What were } \\
\text { your strengths } \\
\text { on each of } \\
\text { these parts? }\end{array}$ & $\begin{array}{l}\text { What did } \\
\text { you struggle } \\
\text { with on each } \\
\text { part? }\end{array}$ \\
\hline $\begin{array}{l}\begin{array}{l}\text { Problem } \\
\text { description }\end{array} \\
\text { Full/Partial/None }\end{array}$ & & \\
\hline $\begin{array}{l}\begin{array}{l}\text { Solution } \\
\text { construction }\end{array} \\
\text { Full/Partial/None }\end{array}$ & & \\
\hline $\begin{array}{l}\text { Logical } \\
\text { progression }\end{array}$ & & \\
\hline
\end{tabular}

FIG. 2. Adaptation of the rubric used in Yerushalmi et al. (2012a-b) for the individual metacognition portion of the problem-solving exercise. From Ref. [10].

ideally work in coordinated groups [16]; however, the situation often reflected individual efforts with some students helping out others as needed [12]. During this time, the instructor would be available for questions, clarifications, etc., while making sure all students in each group were still working towards a solution.

\section{B. Data collection}

The quantitative data consisted of pre-post student responses on the Force Concept Inventory [22] and Colorado Learning Attitudes about Science Survey [20]. These surveys were, respectively, given during the first 50 min of each lab section during the first and last weeks of the semester, for pretest and post-tests, respectively.

At the end of the 45-min session, the instructor would go over the solution using Socratic dialogue with students (who could then use their worked problem solution attempts to answer). Finally, students would spend a few minutes filling out a self-diagnosis rubric, in which they identified strengths and weaknesses to their problem-solving framework attempts $[18,19]$. Once students individually discussed their rubrics with the instructor, they could proceed with the featured lab experiment with their lab partners. Course points were awarded for active participation rather than completion, so as to avoid making the exercise grade dependent. Finally, experimental lab lessons were shortened as needed, in order to ensure students could finish within the allotted $2 \mathrm{~h}$ and $40 \mathrm{~min}$, while still retaining the important core elements of each experiment.

Also given as a post-test was a short-answer feedback survey that asked students several questions about their experience in the course. There were four main questions. The first two questions [10] were used to classify students into their expressed mastery vs performance achievement goals. The first question was "In what ways did you find this (problem-solving) exercise useful towards learning the material in the course?", to which students would respond in terms of how they were mastering a problem-solving framework (or "framework orientation"), in terms of how they believed it helped them perform better on an exam, homework, or other aspect of the course ("performance orientation"), or in terms of something else besides a learning goal ("vague orientation"). Two raters sorted the students' answers into one of these three orientation categories; if they were unsure about a particular student, then the student's answer to the second question, "Do you have any suggestions to make this exercise more useful toward learning the material in the course?" typically served as a means of clarifying the student's primary orientation when answering both questions. The raters were able to come to at least $90 \%$ agreement on a randomly selected subsample of the student population, comprising of 40 students from the Spring 2015 course population, and were able to resolve any remaining differences therein. The two raters were also able to check every semester's course population similarly from that point forward.

The third question of the survey, which will be more of the focus of this paper, was to first ask the students what their major was, and then to ask, "Which sections of the material did you find relate well to the coursework in your major?" Students' answers typically focused on a single section of the course material (e.g., forces or torque), on skills pertinent to their majors (e.g., problem solving skills), or on topics in their majors to which they believed the course applied (e.g., the human body). Other responses included "everything in the course" or alternately "nothing in the course." This last response will be the focus on this paper, by which we will define whether students perceived any relevance to their course (for which any other response would be valid) or no relevance at all (for which they would specifically state that they perceived no relevance).

A total of 218 students over the six sampled semesters submitted a complete dataset of the above items; students who did not (e.g., missing class for the pretests) were omitted. Other students were also omitted if they failed the course outright, or if at least one of their survey responses clearly demonstrated that they were not taking a particular survey seriously (e.g., the CLASS survey's item that requests students to answer a particular choice in order to show they are paying attention to the items).

\section{RESULTS}

\section{A. Distribution of perceptions of relevance vs irrelevance}

The distributions of the student sample into "relevant" (i.e., students who mentioned that they found at least some aspect of the course to be relevant to their majors) and "irrelevant" (i.e., students who stated that they found nothing to be relevant) groups, as well as into subgroups 
TABLE I. Distributions of students who saw the physics course as relevant in some way to their majors vs students who saw the course as irrelevant. Displayed both in terms of raw number and in terms of the percentage out of each group. Originally Table I from Ref. [14]. The term "Irr. \%" in Table I refers to the percentage of each row's student population that is in the "Irrelevant" group, i.e., they do not perceive any relevance of the course to their major.

\begin{tabular}{lccc}
\hline \hline Group (n) & Relevant & Irrelevant & Irr. \% \\
\hline All (218) & 168 & 50 & $22.9 \%$ \\
Biology (91) & 76 & 15 & $16.5 \%$ \\
Health (85) & 66 & 19 & $22.4 \%$ \\
Other Sci (35) & 21 & 14 & $40.0 \%$ \\
Non-Sci (7) & 5 & 2 & $28.6 \%$ \\
Framework (76) & 59 & 17 & $22.4 \%$ \\
Performance (79) & 63 & 16 & $20.3 \%$ \\
Vague (63) & 46 & 17 & $27.0 \%$ \\
\hline \hline
\end{tabular}

by choice of major and by stated learning orientation, are in Table I [14]. (Note that other tables in this paper are adapted from tables in Ref. [14].) The learning orientations, as discussed in Ref. [10], are derived from students' answers to how they found the in-class prelab problem-solving exercise useful; students' responses could be interpreted in a mastery-vs-performance achievement goal set: mastery of the problem-solving framework presented to them (i.e., framework), performance on various in-class measurements, e.g., exams (i.e., performance), or not really expressing any learning goal (i.e., vague).

While the percentage of students who perceive irrelevance does not statistically change between groups for choice of major or for achievement goal, slight differences suggest trends that can be checked on validated survey instruments. For example, it appears that a slightly higher percentage of Vague-oriented students (who expressed no achievement goal) perceive irrelevance than do either of the groups who did express either achievement goal. This mirrors the borderline significance finding in Mason and Bertram [10] that students with a vague orientation had a slightly lower course GPA than did the framework and performance orientations. Also, since the percentage of biology majors perceiving relevance is slightly higher than the percentage of health science majors perceiving relevance, there is some sort of effect as well. Having said all this, it is more appropriate to determine which items on a validated attitudinal survey such as the CLASS survey will exhibit the strongest effect with this variable. We also wish to see whether it corresponds to conceptual understanding of force and motion with the FCI survey.

\section{B. Effect of relevance on FCI performance}

We next examine whether perceived relevance affects pre-post measurements of conceptual understanding of force and motion. Table II examines the FCI pretest,
TABLE II. Average FCI pretest and post-test score percentages and normalized gains, comparing between students with a relevant view of physics and students with an irrelevant view. Standard error is included in parentheses next to each average value for the irrelevant and relevant columns. All comparisons had statistically equal variance ( $F$ test: $p>0.05)$. Adapted from Table 2 in Ref. [14].

\begin{tabular}{lccc}
\hline \hline $\begin{array}{l}\text { FCI } \\
\text { result }\end{array}$ & $\begin{array}{c}\text { Irrelevant } \\
(n=50)\end{array}$ & $\begin{array}{c}\text { Relevant } \\
(n=168)\end{array}$ & $\begin{array}{c}\text { Cohen's } d \\
(p \text { value })\end{array}$ \\
\hline Pre & $24.5 \%(1.7 \%)$ & $26.2 \%(1.1 \%)$ & $0.12(0.44)$ \\
Post & $36.0 \%(2.1 \%)$ & $37.8 \%(1.3 \%)$ & $0.11(0.49)$ \\
$g$ & $+0.15(0.02)$ & $+0.16(0.01)$ & $0.06(0.70)$ \\
\hline \hline
\end{tabular}

post-test, and normalized gain average for the relevant population versus the irrelevant population. The table includes $p$ values for $t$-test results between groups; all comparisons were shown to have statistically similar variances ( $F$ test: $p>0.05)$.

Here, and for the rest of this paper, the normalized gain " $g$ " was calculated for individual pre-post scores as follows, in order to account for negative gains (note all individuals' normalized gains were then averaged):

$$
\begin{gathered}
g=\frac{\text { post } \%-\text { pre } \%}{100 \%-\text { pre } \%} \quad \text { if post }>\text { pre or pre }=0 \\
g=\frac{\text { post } \%-\text { pre } \%}{\text { pre } \%} \quad \text { if post } \leq \text { pre and pre } \neq 0 .
\end{gathered}
$$

Focusing within choice of life science major, an examination of relevance vs irrelevance did not show any statistical differences in force concept understanding between biology majors and life science majors. This is also the case for looking between achievement goal groups, although a moderate effect size $(d \sim 0.3)$ seems to suggest that within the framework-oriented and vague-oriented groups, students who perceived relevance scored slightly better than students who perceived irrelevance. This may offer a bit more detail to the finding that achievement goals did not appear to correlate to FCI pre-post gains [10].

\section{Effect of relevance on class performance}

As with the learning orientations in general (as discussed in Ref. [10]), there is a likelihood that perceived relevance may affect students' pre-post attitudinal shifts. In Table III, an investigation between relevance and irrelevance groups is examined for the CLASS survey, both overall and within each item cluster as defined by Adams et al.: [20] personal interest (PI), real-world connections (RWC), problem solving_-general (PS-G), problem solving-confidence (PS-C), problem solving-sophistication (PS-S), sensemaking/effort (SME), conceptual understanding (CU), and applied conceptual understanding (ACU). Comparisons featured are $t$ tests for statistical significance and Cohen's 


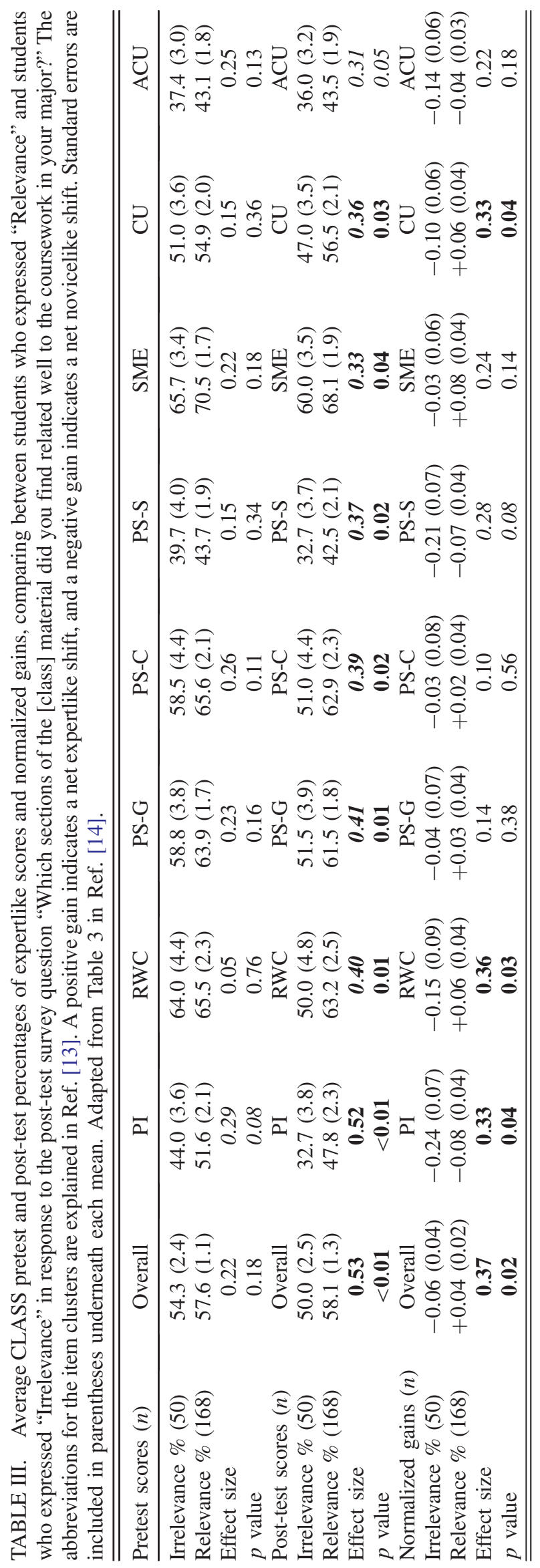


$d$ values for effective size; all comparisons featured were determined to have statistically equal variances using $F$ tests.

In terms of Eqs. (1) and (2), it is more appropriate to think of "gains" like "shifts" for a Likert-scale opinion survey. The overall result across all 39 items is naturally the most robust. Students who perceive relevance have an expertlike shift in gains, which correlates to the post-test showing more expertlike responses than the pretest does. Conversely students who perceive irrelevance have a less expertlike post-test score than pretest, and the gains correspond to a novicelike shift. This also holds for the PI cluster in which both groups have a less expertlike posttest than pretest, and their gains show novicelike shifts, and the CU cluster with similar results. These are two of the three item clusters that show statistical significance on gains. The third is the RWC cluster, in which the relevance group has a lower average post-test response than pretest, but still shows an expertlike gains shift. This is reflective of simple pre- and postaverages not showing how individual students shift expertlike or novicelike, something that happens in most other clusters that do not have significantly different gains.

The results of Table III seem to indicate a rather clear change across most item clusters from pretest to post-test, with significant statistical differences on the post-test across almost all of the item clusters. While perceived relevance does not show a statistical significance on the CLASS pretests, there is a slight trend of the students who perceive relevance having a slightly more expertlike attitude on the pretest. This becomes more statistically clear on the post-test, where students who perceive relevance are demonstrably more expertlike on almost all item clusters, and on average normalized gains, which clarify the uncertainty from the pretests by showing which sets of gains are statistically significant. There is a large effect size for post-test scores $(d=0.53)$ and a moderate effect size for normalized gains $(d=0.37)$ on the overall CLASS survey results. Only a few item clusters showed statistical significance for post-tests and normalized gains, namely, personal interest, real-world connections, and conceptual understanding; the difference in normalized gains is moderate in all three cases $(0.3<d<0.4)$, but the personal interest cluster shows a large effect size on post-test scores $(d=0.53)$.

The results of Table III appear to suggest that certain CLASS item clusters map in particular to students' perceived relevance of physics to their non-physical-science majors. In particular, the strong effect size for "personal interest" for post-test, combined with a more moderate effect size on gains for the same category, suggests that a perception that physics is irrelevant to one's major may be strongly linked to apathy towards physics. This also seems true for the "real-world connections" cluster, in that physics is not readily on a student's mind with regard to their major or to anything else in their worldview. Similarly, the
TABLE IV. Top: Average CLASS pretest and post-test percentages of expertlike scores and normalized gains, comparing students who perceived relevance vs students who did not. Standard errors are in parentheses next to means; please see Table I for respective sample sizes. Bottom: Cohen's $d$ values and $t$-test $p$ values for comparisons between relevant and irrelevant views. Adapted from Table 4 in Ref. [14].

\begin{tabular}{lccc}
\hline \hline & Group & Irrelevant & Relevant \\
\hline Pretest $(\%)$ & Biology & $55.7(3.9)$ & $61.1(1.6)$ \\
& Health & $48.1(3.9)$ & $52.3(1.7)$ \\
Post-test $(\%)$ & Biology & $\mathbf{4 9 . 0}(\mathbf{3 . 8})$ & $\mathbf{6 1 . 7}(\mathbf{1 . 9})$ \\
& Health & $\mathbf{4 3 . 4 ( 3 . 7 )}$ & $\mathbf{5 2 . 5}(\mathbf{2 . 2})$ \\
Gain $(g)$ & Biology & $\mathbf{- 0 . 1 1 ( 0 . 0 6 )}$ & $+\mathbf{0 . 0 6}(\mathbf{0 . 0 3})$ \\
& Health & $-0.09(0.05)$ & $+0.02(0.04)$ \\
\hline \hline
\end{tabular}

Cohen's $d$ effect sizes ( $p$ values from $t$ tests)

\begin{tabular}{lcc}
\hline & Biology & Health \\
\hline Pretest & $0.39(0.16)$ & $0.29(0.27)$ \\
Post-test & $\mathbf{0 . 7 9}(<\mathbf{0 . 0 1})$ & $\mathbf{0 . 5 2}(<\mathbf{0 . 0 5})$ \\
Gains & $\mathbf{0 . 5 8}(<\mathbf{0 . 0 5})$ & $0.39(0.14)$ \\
\hline \hline
\end{tabular}

achievement-goal-related learning orientations featured here were found to correspond to more expertlike shifts for framework-oriented students than for performanceoriented students and vague-oriented students on the CLASS, overall and in particular for the problem-solving item clusters [10].

As discussed in Mason and Bertram [10], biology majors appeared overall to be more prepared for the course and have more expertlike attitudes about learning the course; perhaps perception of relevance may vary between these two groups as well. Table IV examines overall CLASS results within choice of life science major, in order to determine whether biology majors and health science majors may show different trends according to perceived irrelevance.

As Table IV shows, however, the statistical significance appears for both biology majors and health science majors on the CLASS post-test. As for normalized gains, biology majors who perceive relevance show statistically more expertlike gains than students who do not, while health science majors do not demonstrate this statistical significance and only show a moderate effect size.

Table IV indicates that each life science major separately exhibits the pattern within the overall CLASS results in Table III, between relevant-perceiving and irrelevantperceiving students. Both sets of life science majors show no statistical significance on the pretest.

However, there is a large effect size and significance on the posttest for both sets of majors, with more expertlike scores from relevant-perceiving students in both cases. With regard to CLASS item clusters, biology majors who perceived relevance had statistically higher post-test scores and normalized gains on the PI and RWC clusters, as well as on the sense making-effort (SME) 
TABLE V. Top: Average CLASS pretest and post-test percentages of expertlike scores and normalized gains, comparing students who perceived relevance vs students who did not. Standard errors are in parentheses next to means; please see Table I for respective sample sizes. Bottom: Cohen's $d$ values and $t$-test $p$ values for comparisons between relevant and irrelevant views. Adapted from Table 5 in Ref. [14].

\begin{tabular}{lllc}
\hline \hline & \multicolumn{1}{c}{ Group } & Irrelevant & Relevant \\
\hline Pretest (\%) & Framework & $53.4(3.8)$ & $58.1(1.6)$ \\
& Performance & $57.4(5.0)$ & $57.1(1.9)$ \\
& Vague & $52.1(3.5)$ & $57.6(2.4)$ \\
Post-test (\%) & Framework & $54.9(4.5)$ & $62.6(2.0)$ \\
& Performance & $46.5(4.8)$ & $56.1(2.2)$ \\
& Vague & $48.2(3.3)$ & $54.9(2.6)$ \\
Gains (g) & Framework & $+0.05(0.07)$ & $+0.13(0.04)$ \\
& Performance & $\mathbf{- 0 . 1 8 ( \mathbf { 0 . 0 6 } )}$ & $+\mathbf{0 . 0 1}(\mathbf{0 . 0 4})$ \\
& Vague & $-0.06(0.05)$ & $-0.02(0.04)$ \\
\hline \hline
\end{tabular}

Cohen's $d$ effect sizes ( $p$ values from $t$ tests)

\begin{tabular}{lccc}
\hline & Framework & Performance & Vague \\
\hline Pretest & $0.35(0.21)$ & $0.02(0.94)$ & $0.35(0.22)$ \\
Post-test & $0.47(0.10)$ & $0.53(0.07)$ & $0.40(0.17)$ \\
Gains & $0.26(0.35)$ & $\mathbf{0 . 6 8}(\mathbf{0 . 0 2})$ & $0.18(0.54)$ \\
\hline \hline
\end{tabular}

cluster, with large effect sizes for these three clusters $(0.6<d<0.85$ for post-test comparisons, $0.5<d<0.8$ for gains comparisons).

Table V shows CLASS results within learning orientations between perceived relevance and irrelevance. We are particularly interested to see if learning orientations and perceived relevance influence each other, as it appears both items can be considered factors that influence attitudinal shifts. However, perceived relevance appears to only be a factor for performance-oriented students; those who perceived relevance to their majors did not experience much shifting, while those who did not experienced a novicelike shift. The effect size between relevance and irrelevance for performance-oriented students is large $(d=0.68)$. On the other hand, framework-oriented students are only mildly influenced by perceived relevance ( $d=0.26$ on gains), with a slightly expertlike shift occurring for both relevance and irrelevance groups. Vague-oriented students had a slight novicelike shift regardless of perceived relevance. Within the CLASS item clusters, the performance-oriented students had statistical significance $(p<0.05)$ or borderline significance $(0.05<p<0.1)$ across all item clusters, with students who perceived irrelevance having a more novicelike shift in each case.

\section{DISCUSSION}

\section{A. Conclusions}

In terms of the first research question, namely, whether students' perceived relevance had an effect on their FCI pre-post outcomes, the null argument that there is no difference on the FCI appears to be accepted, at least within the overall sample size of 218 students as split into 168 students who perceived at least some form of relevance and 50 students who explicitly said they did not. There was no statistical significance between groups on either the pretest or the post-test, and the effect sizes on both the pretest and the posttest were weak. A subdivision into item clusters, choice of life science major, or learning goals, as was done for CLASS results, did not show any significant results either, and so the data from that particular comparison is omitted.

As Table II's normalized gains seem to strongly indicate, the larger factors appear to be the particularly low pretest scores from this sample (which are close to $20 \%$, amounting to the average score for randomly choosing from 5 answers for each of the multiple-choice questions). This in turn skews the normalized gain calculation, as the denominator of this calculation (100\%-prescore) is larger than are the pretest scores of many calculus-based introductory physics courses' gains, whether within traditional instruction or within research-based course transformations [37].

With regard to the second research question, on the other hand, there is a strong difference on CLASS pre-post attitudinal shifts. While students who perceived relevance were statistically similar to students who did not perceive relevance at the beginning of the course, the pre-post shifts (shown both by post-test results and by normalized gains) demonstrate that students who do not perceive relevance experience a slight novicelike shift overall, as opposed to a slight expertlike shift for students who do perceive relevance. In particular, the strongest results within the CLASS item clusters appear within the personal interest and real-world connections clusters. This appears to corroborate students' self-reported perceptions that nothing in the physics course applies to their major, by suggesting that this group of students is (a) less likely to be interested in physics (a lack of perceived relevance may be conflated with a more straightforward lack of interest in the subject) and (b) less likely to perceive real-world connections (including to their own majors) of physics.

We move from here into the third research question, namely whether perceived relevance has an effect within choice of major or within learning orientation. An analysis of relevance vs irrelevance within both biology majors and health science majors appears to show a slightly stronger trend for biology majors than for health science majors. While both major groups demonstrate a statistical difference in posttest results, only the biology majors show statistical difference on normalized gains, while health science majors do not. That having been said, perceived relevance does appear to matter for both sets of life science majors.

As for achievement-goal-based learning orientations, perceived relevance appears to make a difference specifically for performance-oriented students. Those that 
perceive relevance of physics to their majors do not experience a novicelike shift (or for that matter, much of a shift at all), while those that do not perceive relevance experience a more pronounced novicelike shift. Therefore, even though some students may be more concerned about their course grade than about mastering the material, they may at least retain their attitudes towards learning physics without a novicelike shift if they can perceive that at least something within a physics class pertains to their major. On the other hand, perceived relevance only seems to have a mild relative effect within framework-oriented students (whose focus on mastery gives them an expert-like shift in either case of perceiving relevance or not) and within vague-oriented students (who do not state any achievement goal and who experience a novicelike shift in either case).

Overall, perception of relevance appears to be a cofactor alongside achievement-goals-driven learning orientations for the expert-novice shifts within attitudinal survey data. It appears that aspects of student mindset do influence perceptions of learning physics; however, it is not so clear whether student mindset affects conceptual understanding (at least with regard to the force and motion topics within the FCI).

\section{B. Limitations of the study}

The study's results are limited to the respective scopes of the two survey instruments, namely, the FCI and the CLASS. The FCI focuses on force and motion topics, not necessarily upon energy topics or other topics that may be covered within a first-semester course. The low pretest scores on the FCI also suggest that the student population at the host institution (a regional four-year state university with a primary emphasis on undergraduate education) may not match student populations in published studies at more research-oriented institutions.

There is also the limitation of the host university's status as a primarily undergraduate institution with a regional focus. This presented logistic issues that prevented collection of a large sample size, namely, that only 48-72 students were available to the author for any given semester, such that multiple semesters were required to collect at least 200 students. In addition, the institution type influences both the meaning of the results (in that the students involved do not necessarily have the same demographics, career goals, etc., as, e.g., students in a large research university) and the feasibility of recommended means to address the problem. For an example of the latter issue, the featured health science majors were a mixture of majors that somewhat resembled premedical and other human-anatomy-related biology tracks (e.g., pre-physical therapy and pre-occupational therapy), while other majors did not even clearly have a physical science application at all (e.g., the health administration track is akin to a business major). With these allowances in mind, the results may prove more useful for primarily-undergraduate state universities than for other institution types.

The post-test feedback survey had its own limitations as well. First, as it was not a validated research instrument, the findings with the CLASS survey's personal interest and real-world connections item clusters serve as a form of validation, in the sense that perceived relevance is closely related to the expert-novice shifts within these two clusters. Second, because the feedback survey was not a pretest instrument, and because there were no statistically significant differences between groups on the CLASS in either case, it is unknown whether either perceived relevance or achievement goals are static or growth-related throughout the semester [1,9]. The relative trends on the CLASS pretest appear to suggest that, with a larger sample size, it could be roughly determined whether perceived relevance may be more likely to be static or growth related.

\section{Discussion}

Even given the limitations within the FCI data, the results to reinforce the notion that expertlike beliefs are not necessarily correlated with strong content understanding of physics. The CLASS is a validated instrument for students' perceptions of learning physics; that being said, there have been recent discussions about whether attitudinal changes actually reflect students' ability to perform well in the course, e.g., item response theory explorations of the CLASS survey which suggest that high performance in the course does not necessarily correlate with expertlike beliefs [38]. Previous work that looked more closely at this student sample's overall course grades [10] showed only a borderline significant argument that students who stated an achievement goal (either mastery related or performance related) were somewhat more successful than students who did not (i.e., the vague-oriented group).

Due to IRB limitations on this follow-up study, the author cannot provide a similar discussion of course grades' relationship with perceived course relevance; a follow-up study with newer data and the ability to measure this will shed light on this issue. If it turns out that perceived relevance is related to course performance, the next goal would be to investigate how to convince students over the course of the semester that introductory physics is indeed relevant to their majors; if it does not, then the issue may simply be that a single introductory-level course is not a large enough scope to observe the effects of perceived relevance on course grades, and a more longitudinal study may be necessary.

Furthermore, a pretest measurement of the mindset variables, in combination with the existing post-test feedback survey, may contribute to determining whether both perceived relevance and achievement goals are static or growth related. Perceived relevance in particular may change for students who become convinced as the semester progresses that introductory physics is relevant to their 
majors. If so, these particular students' backgrounds (e.g., choice of major) can guide instructors towards targeting course development towards motivating students through recognizing the course material's relevance to them.

\section{ACKNOWLEDGMENTS}

A. J. M. thanks the UCA Department of Physics and Astronomy for funding support.
[1] C. Dweck, Mindset: The New Psychology of Success (Ballantine, New York 2007).

[2] M. Stuckey, A. Hofstein, R. Mamlok-Naaman, and I. Eilks, The meaning of 'relevance' in science education and its implications for the science curriculum, Studies Sci. Educ. 49, 1 (2013).

[3] D. Domert, J. Airey, C. Linder, and R. L. Kung, An exploration of university physics students' epistemological mindsets towards the understanding of physics equations, Nordic Studies Sci. Educ. 3, 15 (2007).

[4] A. Little, B. Humphrey, A. Green, A. Nair, and V. Sawtelle, Exploring mindset's applicability to students' experiences with challenge in transformed college physics courses, Phys. Rev. Phys. Educ. Rev. 15, 010127 (2019).

[5] B. Hofer and P. Pintrich, The development of epistemological theories: Beliefs about knowledge and knowing and their relation to learning, Rev. Educ. Res. 67, 88 (1997).

[6] E. F. Redish, J. M. Saul, and R. N. Steinberg, Student expectations in introductory physics, Am. J. Phys. 66, 212 (1998); D. Hammer and A. Elby, Epistemological resources, in Proceedings of the Fourth International Conference of the Learning Sciences, edited by B. Fishman and S. O' ConnorDivelbiss (Erlbaum, Mahwah, NJ, 2000), pp. 237-290.

[7] D. E. Gardner and G. M. Bodner, Existence of a problemsolving mindset among students taking quantum mechanics and its implications, in ACS Symposium Series Vo. 973, "Advances in Teaching Physical Chemistry" (American Chemical Society, Washington, DC, 2007), pp. 155-173; P. Irving and E. Sayre, Becoming a physicist: The roles of research, mindsets, and milestones in upper-division student perceptions, Phys. Rev. ST Phys. Educ. Res. 11, 020120 (2015).

[8] Z. Hazari, G. Potvin, R. Tai, and J. Almarode, For the love of learning science: Connecting learning orientation and career productivity in physics and chemistry, Phys. Rev. ST Phys. Educ. Res. 6, 010107 (2010).

[9] D. Belenky and T. Nokes-Malach, Motivation and transfer: The role of mastery-approach goals in preparation for future learning, J. Learn. Sci. 21, 399 (2012); D. M. Belenky and T. J. Nokes-Malach, Mastery-approach goals and knowledge transfer: An investigation into the effects of task structure and framing instructions, Learning Indiv. Diff. 25, 21 (2013).

[10] A. Mason and C. Bertram, Consideration of learning orientations as an application of achievement goals in evaluating life science majors in introductory physics, Phys. Rev. Phys. Educ. Res. 14, 010125 (2018).

[11] A. J. Mason, Potential relationship of chosen major to problem solving attitudes, and course performance, in
Proceedings of the 2015 Physics Education Research Conference, College Park, MD, edited by A. D. Churukian, D. L. Jones, and L. Ding (AIP, New York, 2015).

[12] A. J. Mason and C. A. Bertram, Potential relationship of epistemic games to group dynamics and learning orientations towards physics problem solving, in Proceedings of the 2016 Physics Education Research Conference Sacramento, CA, edited by D. L. Jones, L. Ding, and A. Traxler (2016).

[13] C. A. Bertram and A. J. Mason, The effect of students' learning orientations on performance in problem solving pedagogical implementations, in Proceedings of the 2017 Physics Education Research Conference Cincinnati, OH, edited by L. Ding, A. Traxler, and Y. Cao (AIP, New York, 2017).

[14] A. J. Mason, Learning goals, and perceived irrelevance to major within life science majors in introductory physics, in Proceedings of the 2019 Physics Education Research Conference Provo, UT, edited by Y. Cao, S. Wolf, and M. B. Bennett (AIP, New York, 2019).

[15] D. Bennett, L. Roberts, and C. Creagh, Exploring possible selves in a first-year physics foundation class: Engaging students by establishing relevance, Phys. Rev. Phys. Educ. Res. 12, 010120 (2016).

[16] P. Heller and M. Hollabaugh, Teaching problem solving through cooperative grouping. Part 2: Designing problems and structuring groups, Am. J. Phys. 60, 637 (1992).

[17] P. Heller, R. Keith, and Anderson, Teaching problem solving through cooperative grouping. Part 1: Group versus individual problem solving, Am. J. Phys. 60, 627 (1992).

[18] E. Yerushalmi, E. Cohen, A. Mason, and C. Singh, What do students do when asked to diagnose their mistakes? Does it help them? I. An atypical quiz context, Phys. Rev. Phys. Educ. Res. 8, 020109 (2012).

[19] E. Yerushalmi, E. Cohen, A. Mason, and C. Singh, What do students do when asked to diagnose their mistakes? Does it help them? II. A more typical quiz context, Phys. Rev. Phys. Educ. Res. 8, 020110 (2012).

[20] W. Adams, K. Perkins, N. Podolefsky, M. Dubson, N. Finkelstein, and C. Wieman, New instrument for measuring student beliefs about physics and learning physics: The Colorado Learning Attitudes about Science Survey, Phys. Rev. ST Phys. Educ. Res. 2, 010101 (2006).

[21] L. M. Daniels, T. L. Haynes, R. H. Stupnisky, R. P. Perry, N. E. Newall, and R. Pekrun, Individual differences in achievement goals: A longitudinal study of cognitive, emotional, and achievement outcomes, Contemp. Educ. Psychol. 33, 584 (2008). 
[22] D. Hestenes, M. Wells, and G. Swackhamer, Force concept inventory, Phys. Teach. 30, 141 (1992).

[23] A. Collins, J.S. Brown, and S. E. Newman, Cognitive apprenticeship: Teaching the craft of reading, writing, and mathematics, in Knowing, Learning, and Instruction: Essays in Honor of Robert Glaser, edited by L. B. Resnick (Erlbaum Associates, Inc., Hillsdale, NJ, 1989), pp. 453-494.

[24] J. D. Bransford and D. L. Schwartz, Rethinking transfer: A simple proposal with multiple implications, Rev. Res. Educ. 24, 61 (1999).

[25] P. Heller and K. Heller, Cooperative Group Problem Solving in Physics (Brooks/Cole Publishing Company, Pacific Grove, California, 2001).

[26] A. Nair and V. Sawtelle, Operationalizing relevance in physics education: Using a systems view to expand our conception of making physics relevant, Phys. Rev. Phys. Educ. Res. 15, 020121 (2019).

[27] J. Massolt and A. Borowski, Perceived relevance of university physics problems by pre-service physics teachers: personal constructs, Int. J. Sci. Educ. 42, 167 (2020).

[28] G. Kortemeyer, The challenge of teaching introductory physics to premedical students, Phys. Teach. 45, 552 (2007).

[29] E. F. Redish et al., NEXUS/Physics: An interdisciplinary repurposing of physics for biologists, Am. J. Phys. 82, 368 (2014).

[30] C. H. Crouch and K. Heller, Introductory physics in biological context: An approach to improve introductory physics for life science students, Am. J. Phys. 82, 378 (2014).

[31] E. Mylott, E. Kutschera, J. Dunlap, W. Christensen, and R. Widenhorn, Using biomedically relevant multimedia content in an introductory physics course for life science and pre-health students, J. Sci. Educ. Technol. 25, 222 (2016).
[32] E. Redish and T. Cooke, Learning each other's ropes: Negotiating interdisciplinary authenticity, CBE Life Sci. Educ. 12, 175 (2013).

[33] M. Klymkowsky and M. Cooper, Now for the hard part: The path to coherent curricular design, Biochem. Mol. Biol. Educ. 40, 271 (2012); D. Meredith and E. Redish, Reinventing physics for life science majors, Phys. Today 66, No. 7, 38-43 (2013).

[34] C. Crouch, P. Wisittanawat, M. Cai, and K. A. Renninger, Life science students' attitudes, interest, and performance in introductory physics for life sciences: An exploratory study, Phys. Rev. Phys. Educ. Res. 14, 010111 (2018).

[35] B. Geller, C. Turpen, and C. Crouch, Sources of student engagement in Introductory Physics for Life Sciences, Phys. Rev. Phys. Educ. Res. 14, 010118 (2018).

[36] S. Kanim and X. C. Cid, Demographics of physics education research, Phys. Rev. Phys. Educ. Res. 16, 020106 (2020); also see C. Middleton, Skewed student demographics distort physics education studies, Phys. Today, Careers and Education (2020). Archived at https:// physicstoday.scitation.org/do/10.1063/PT.6.5.20200826a/ full/, retrieved 9/26/2020.

[37] R. Hake, Interactive-engagement versus traditional methods: A six-thousand-student survey of mechanics test data for introductory physics courses, Am. J. Phys. 66, 64 (1998).

[38] E. Christman, P. Miller, and J. Stewart, Exploring the CLASS with item response theory, in Proceedings of the 2020 Physics Education Research Conference, virtual conference, edited by S. Wolf, M. Bennett, and B. Frank (AIP, New York, 2020). 